\title{
$\mathrm{UL} 268$ 화원에 의한 연기입자의 광학적 특성
}

\author{
지승욱 $\cdot$ 이종화*广 \\ 영남대학교 대학원, *호남대학교 소방행정학과
}

\section{Optical Properties for Smoke Particles of Fire Sources According to UL 268}

\section{Seung-Wook Jee $\cdot$ Jong-Hwa Lee ${ }^{* \dagger}$}

\author{
Graduate School, Yeungnam University \\ * Department of Fire Service Administration, Honam University
}

(Received October 2, 2013; Revised April 22, 2014; Accepted April 22, 2014)

$$
\text { 요 약 }
$$

본 논문은 화재감지는 물론 화원까지 구별할 수 있는 광전식 연기감지기 개발을 위한 기초 연구이다. 이를 위해, 현재 광전식 연기감지기에 많이 사용되고 있는 광원과 센서를 사용하여 광학챔버를 제작하였으며, UL 268에서 연기감지기를 시험할 때 사용되는 세 가지 화원(종이화원, 목재화원, 인화성 액체화원)을 대상으로 각 화원별 광학적 특징을 구하였다. 그 결과 종이화원과 목재화원은 산란에 큰 차이를 보였으며, 인화성 액체화원은 소광의 원인이 다름을 알 수 있었다.

\begin{abstract}
This paper is basic study for development of the photoelectric-type smoke detector that is able to distinguish fire source as well as fire detection. For this subject, Light source and sensor which is normally used for the conventional smoke detector are assembled for the optical chamber. Using 3 type of the test fires (the paper fire, the wood fire, the flammable liquid fire) this paper attempts to find optical properties of each fire. These 3 type of fire are used in the testing of smoke detector according to UL 268 standard. As the result, there are disambiguated between the paper fire and the wood fire in scattering and reason of extinction in the flammable liquid fire is different from that of the paper and the wood fire.
\end{abstract}

Keywords : Smoke particles, Extinction, Scattering, Optical properties

\section{1. 서 론}

감지기는 화재 시 발생되는 열, 연기, 불꽃 등 연소생성 물을 자동으로 감지하여 자동화재탐지설비의 수신기로 발 신하는 장치이다. 특히, 연기감지기는 화재를 조기에 발견 할 수 있어 초기 피난유도가 유리하기 때문에 많이 사용되 고 있다. 연기감지기는 이온화식과 광전식이 주로 생산되 고 있지만, 경제적인 이유와 방사능 문제로 광전식 연기감 지기가 많이 사용된다. 우리나라에서 판매되고 있는 모든 연기감지기는 형식승인을 얻게 되는데, 2007년부터 2012 년까지 형식승인을 얻은 연기감지기 중 약 $95 \%$ 가 광전식 이었다 ${ }^{(1-5)}$.

광전식 연기감지기에 관한 연구로 1990년대 $\mathrm{Mie}$ 산란 등을 이용한 연기입자 구별에 관한 연구가 진행되었다. 이 들 연구는 무엇보다 편광된 단색광을 필요로 한다. 또한,

\footnotetext{
'Corresponding Author, E-Mail: Buldori@honam.ac.kr TEL: +82-62-940-5535, FAX: +82-62-940-5202
}

연기입자는 그 크기가 고르지 못하고, 입자들끼리 부착되 는 경우도 많아 실용화에는 한계가 있었다. 그 결과 현재 는 온도 센서나 $\mathrm{CO}$ 센서 등 다른 센서들과 함께 사용하여 비화재보를 줄이기 위한 연구가 많이 진행되고 있다 ${ }^{(6-9)}$.

이에 본 논문은 저 비용으로 연기감지는 물론 연기를 분 석하여 그 화원을 구별하고자 시도하였다. 이를 위해 광원 과 센서는 현재 광전식 연기감지기에 많이 사용되는 LED (Light Emitting Diode)와 포토다이오드를 이용하였고, 세 가지 화원에 대하여 광학적 특징을 구하고자 하였다.

\section{2. 관련 이론}

\section{1 흡수와 산란}

소광(Extinction)은 전송 중인 광선(Light beam)이 에어 로솔(Aerosol)에 의해 빛이 방출되거나 감쇠되는 현상이다.

ISSN: $1738-7167$

DOI: http://dx.doi.org/10.7731/KIFSE.2014.28.2.009 


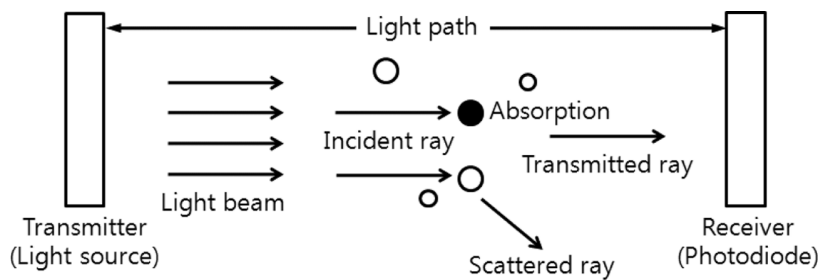

Figure 1. Light scattering and absorption by particles.

Figure 1과 같이 광선이 에어로솔을 통과할 때 에어로솔 입자에 의해 일부는 흡수(Absorption)되고, 일부는 산란 (Scattering)된다. 매우 검은 연기입자(검댕, Soot)는 흡수 가, 그렇지 않은 연기입자는 산란이 소광의 주요 원인이 된다 ${ }^{(9-11)}$.

산란은 에어로솔 입자 직경과 광파장의 관계에 따라 세 가지 영역으로 나뉘어 해석된다. 에어로솔 입자의 직경이 광파장보다 훨씬 작은 영역은 Rayleigh 이론으로 해석되 고, 에어로솔 입자의 직경이 광파장보다 훨씬 큰 영역은 기하광학을 이용한 굴절된 광선의 궤적을 추적하는 방법 으로 해석된다. 에어로솔 입자의 직경과 광파장이 서로 유 사하여 산란이 복잡한 중간영역은 $\mathrm{Mie}$ 이론으로 해석된 다 ${ }^{(10,11)}$.

연기 입자를 측정할 때도 광원의 파장과 연기 입자의 직 경에 따라 위에서 언급한 세 영역으로 나누어 서로 다른 이론을 적용하게 된다(11).

\section{2 연기입자}

Figure 2는 UL 268에 따라 만들어진 종이화원과 목재화 원에서 발생된 연기를 포집하여 주사전자현미경(Scanning electron microscope, $\mathrm{SEM}$ )으로 촬영한 영상이다. 종이화 원의 경우 연기입자들의 크기가 비교적 일정하지만 목재 화원의 경우 연기입자들의 크기 차이가 매우 크다. 특히 불완전 연소로 추정되는 입자의 경우 다른 입자에 비해 그 크기가 수 십 배에 달하는 것을 볼 수 있다 ${ }^{(12)}$.

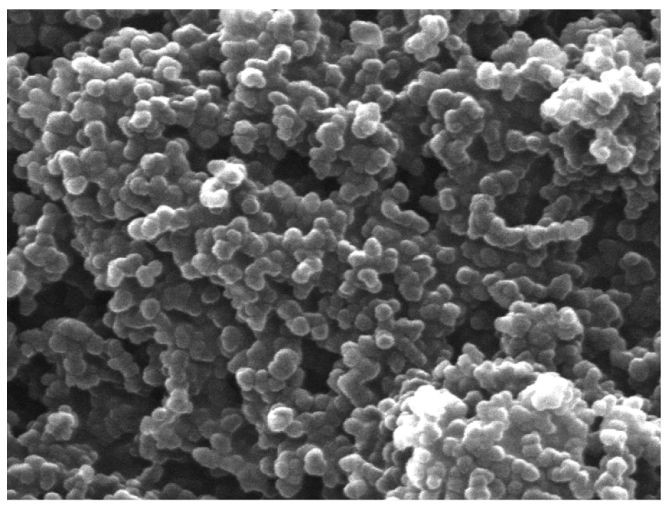

(a) Paper fire

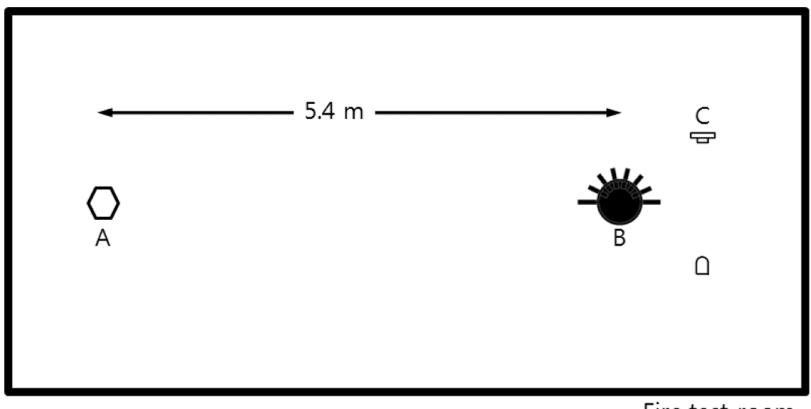

A : Test fire

$B$ : Test chamber

(a) A top view

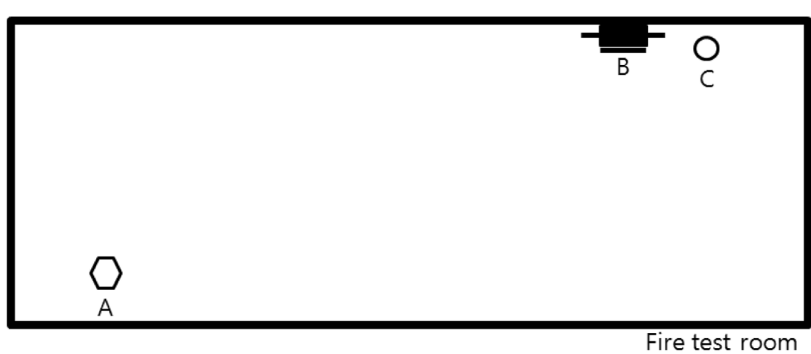

(b) A front view

Figure 3. Experiment setup diagram.

\section{3. 실험장치 및 방법}

실험은 Figure 3과 같이 가로 $7.0 \mathrm{~m}$, 세로 $3.4 \mathrm{~m}$, 높이 $2.4 \mathrm{~m}$ 의 화재시험장(Fire test room)에서 진행되었다. $\mathrm{A}$ 는 시험화원(Test fire)이고, 이로부터 $5.4 \mathrm{~m}$ 떨어진 곳에 연기 감지용 챔버 $\mathrm{B}$ 를 설치하였다. $\mathrm{C}$ 는 시험화원으로부터 발생 된 연기가 UL 268이 제시하는 조건을 만족하는지 그 여 부를 측정하기 위해 설치한 램프와 포토셀 장치이다. UL 268 의 조건을 만족하는 연기로 실험한 결과만을 본 연구 의 실험결과로 채택하였다.

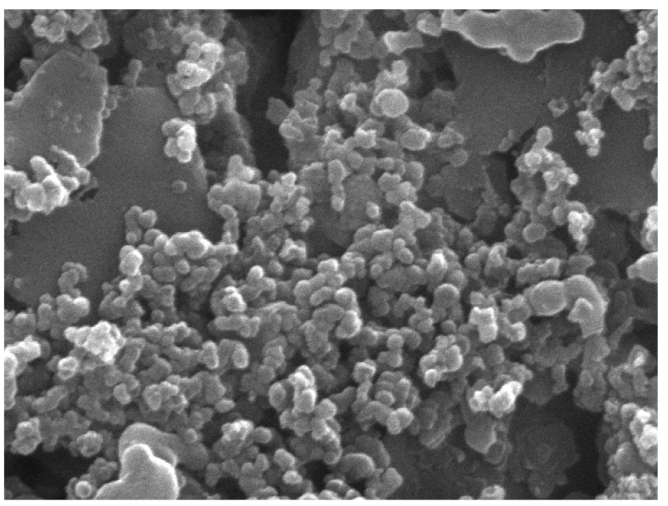

(b) Wood fire

Figure 2. SEM images of smoke particles ${ }^{(12)}$. 


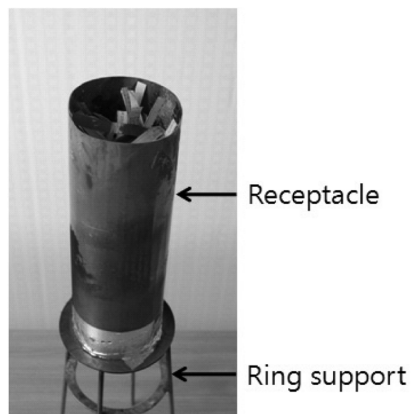

(a) Paper fire

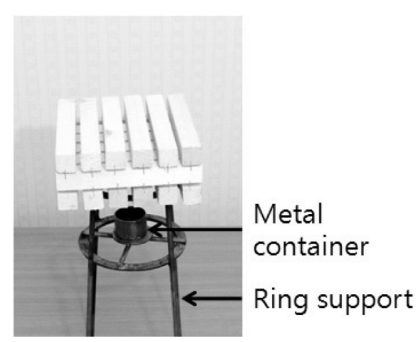

(b) Wood fire

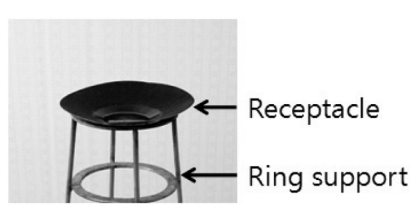

(c) Flammable liquid fire

Figure 4. Test fires.

실험에 사용된 시험화원 $\mathrm{A}$ 는 모두 세 종류 이다. 이들은 UL (Under writers Laboratories Inc.) 268에서 연기감지기 시험에 사용되는 것들로 다음과 같이 제조되었다 ${ }^{(13)}$.

먼저 $10 \times 102 \mathrm{~mm}$ 크기로 자른 흑백 신문 $42.6 \mathrm{~g}$ 을 0.8 $\mathrm{mm}$ 두께의 박판으로 만든 직경 $102 \mathrm{~mm}$, 높이 $300 \mathrm{~mm}$ 의 리셉터클에 넣는다. 이를 종이화원(Paper fire)이라고 한다. 종이화원은 Figure 4(a)와 같이, 지지대를 이용하여 화재
시험장 바닥으로부터 $300 \mathrm{~mm}$ 띄워 설치되었다. 두 번째 시험화원은 목재화원 $($ Wood fire)이다. $19.1 \times 19.1 \times 152 \mathrm{~mm}$ 크기의 목재 6 개를 일정한 간격으로 배치하여 한 층을 이 루게 하고, 이를 Figure 4(b)와 같이 서로 직각이 되게 3 층으로 쌓아 만들었다. 목재화원은 $4 \mathrm{ml}$ 의 점화보조제 $(5 \%$ 의 메탄올 $+95 \%$ 의 에탄올)를 담고 있는 직경 $38 \mathrm{~mm}$, 깊 이 $25.4 \mathrm{~mm}$ 의 금속용기 바닥으로부터 $89 \mathrm{~mm}$ 위에, 화재

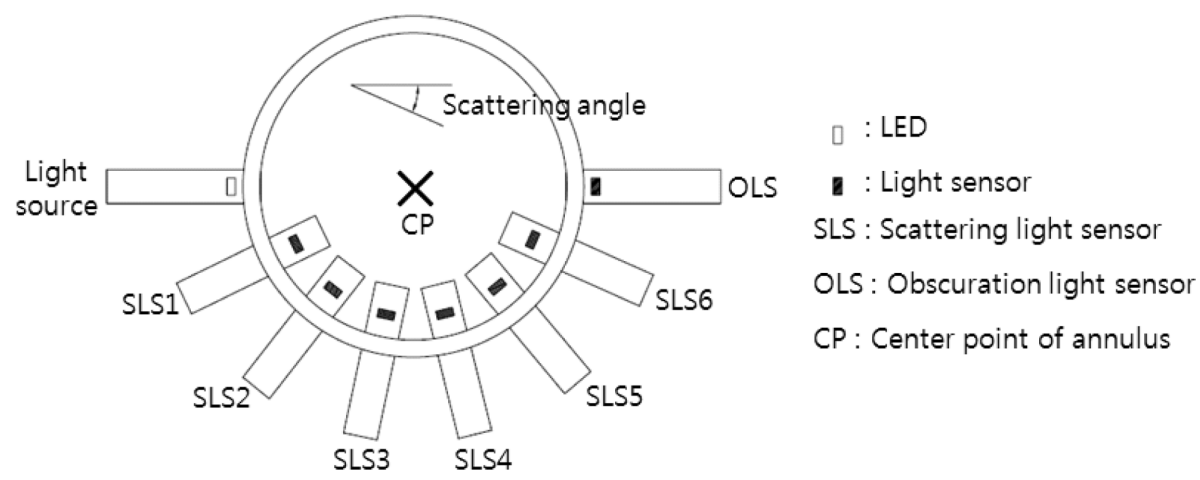

(a) A plan view

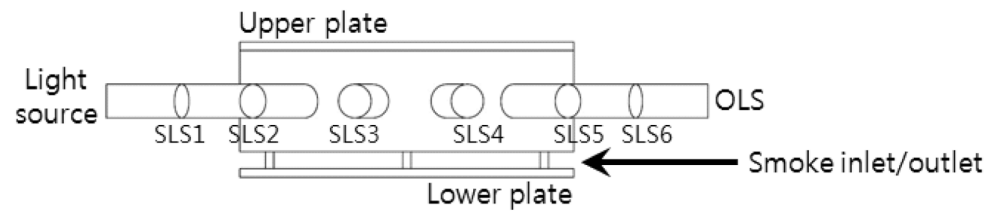

(b) A side view

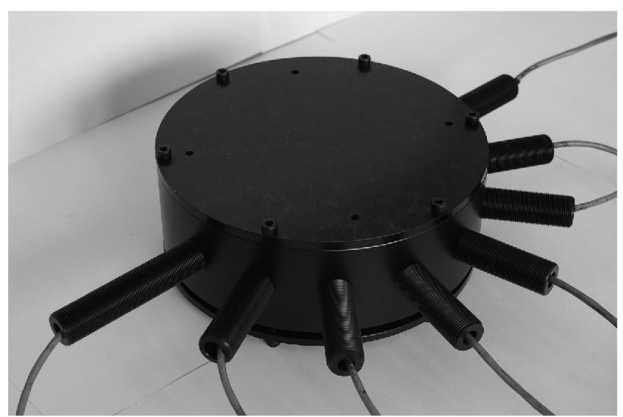

(c) Photo of the optical chamber

Figure 5. Schematic diagram of the optical chamber. 
시험장 바닥으로부터는 $300 \mathrm{~mm}$ 띄워 설치되었다. 세 번 째 시험화원은 인화성 액체화원(Flammable liquid fire)이 다. $25 \%$ 의 톨루엔과 $75 \%$ 의 헵탄을 혼합하고, Figure 4(c) 와 같이, 이를 $0.635 \mathrm{~mm}$ 스테인리스 강판으로 만든 리셉 터클(직경 $158 \mathrm{~mm}$, 바닥 직경 $25.4 \mathrm{~mm}$, 깊이 $32 \mathrm{~mm}$ 의 둥근형태)에 담겨져 화재시험장 바닥으로부터 $300 \mathrm{~mm}$ 띄 워 설치되었다.

연기감지용 챔버 $\mathrm{B}$ 는 Figure 5 와 같이 제작되었다. 광원 (Figure 5에서 Light source)은 재래식 연기감지기에 많이 사용되고 있는 파장 $960 \mathrm{~nm}$ 의 $\mathrm{LED}$ 를 집광렌즈와 함께 원 통모향의 거치대에 설치하여 사용하였다. 수광부 역시 산 란광식 연기감지기에 많이 사용되는 포토다이오드를 원통 형 거치대에 설치하여 사용하였다. 6개의 광센서들(Figure 5 에서 SLS1-SLS6)이 내경 $180 \mathrm{~mm}$ 의 원통의 한쪽에 설치 되었다. 소광량을 측정하기 위해 또 하나의 광센서(Figure 5 에서 $\mathrm{OLS}$ )가 추가되었다. $\mathrm{LED}$ 와 OLS는 각각 중심으로 부터 $90 \mathrm{~mm}$ 떨어뜨려 서로 마주보게 설치하였고, 6 개의 $\mathrm{SLS}$ 들은 중심으로부터 $60 \mathrm{~mm}$ 떨어뜨려 설치하였다. OLS, 중심점(Figure 5(a)의 'CP') 및 SLS가 이루는 각을 산란각 (scattering angle)이라고 할 때, SLS6는 $26^{\circ}, \mathrm{SLS} 5$ 는 $52^{\circ}$, $\mathrm{SLS} 4$ 는 $78^{\circ}, \mathrm{SLS} 3$ 는 $104^{\circ}, \mathrm{SLS} 2$ 는 $130^{\circ}, \mathrm{SLS} 1$ 은 $156^{\circ}$ 가 되도록 설치함으로써 서로 등 간격이 되게 하였다. 원통 (annulus)은 Figure 5(b)와 같이 상판과 하판을 부착한 후, 화재시험장의 천장(Figure 3 의 $\mathrm{B}$ 부분)에 설치하였다. 7 개 의 광센서로부터 입력된 신호는 low-pass filter (차단주파 수 $0.25 \mathrm{~Hz}$ )를 거쳐 데이터 취득장치 (sampling time: $\max$ $1 \mathrm{~s}$, measuring accuracy: $\pm 0.1 \%$ of $\mathrm{rdg}+2$ digits)에 저장 된다.

실험은 세 가지 시험화원 중 하나를 Figure 3의 A 위치 에서 점화하면서 시작되며, $240 \mathrm{~s}$ 동안 진행되었다. 7 개의 광센서로부터 $3 \mathrm{~s}$ 간격으로 데이터를 읽고, 이를 데이터 취득장치에 저장하였다.

\section{4. 실험결과 및 분석}

Figure 6은 종이화원에 대한 실험결과를 보여준다. OLS 를 보면 $120 \mathrm{~s}$ 부터 $160 \mathrm{~s}$ 사이에 연기입자에 의한 소광량 이 매우 많은 것을 볼 수 있다. 이 때 SLS들에 감지된 산 란량도 매우 크다. 특히 SLS6에 산란이 집중된 것을 볼 수 있다.

Figure 7은 목재화원에 대한 실험결과를 보여준다. OLS 를 보면 $80 \mathrm{~s}$ 부터 지속적으로 연기량이 증가하는 것을 볼 수 있다. 산란광의 경우 간헐적이지만 모든 SLS들에서 검 출되는 것을 볼 수 있다. 다만, 종이화원에 비해 검출되는 산란량이 적었다.

종이화원에 의한 연기의 경우 SLS6가 감지하는 산란량 이 매우 크다. 즉, 산란각의 편차가 적다. 이것은 종이화원 에 의한 연기입자들의 크기가 고르다는 것을 의미한다. 반

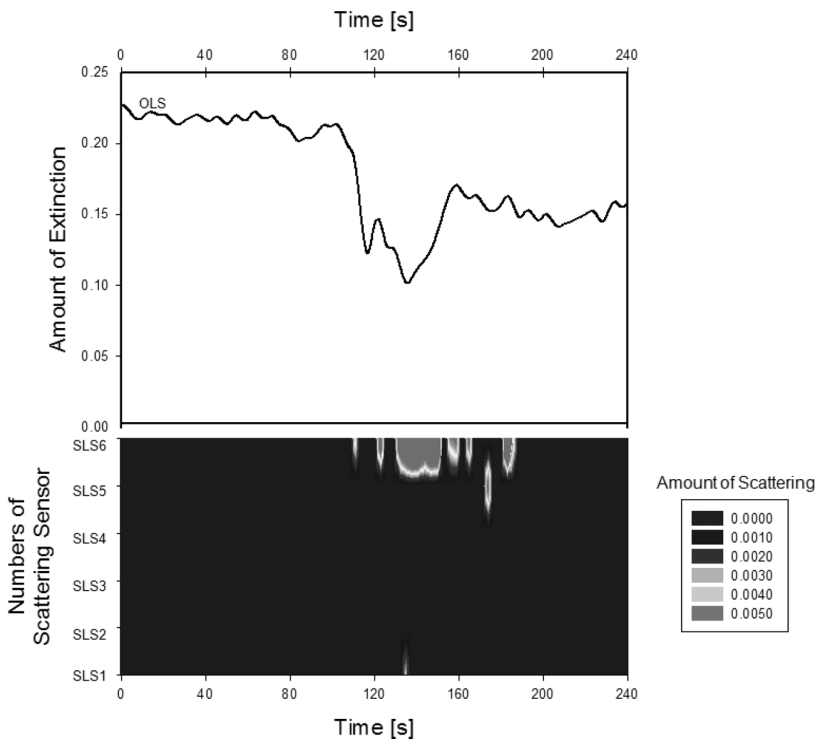

Figure 6. Amount of scattering and extinction for the paper fire.

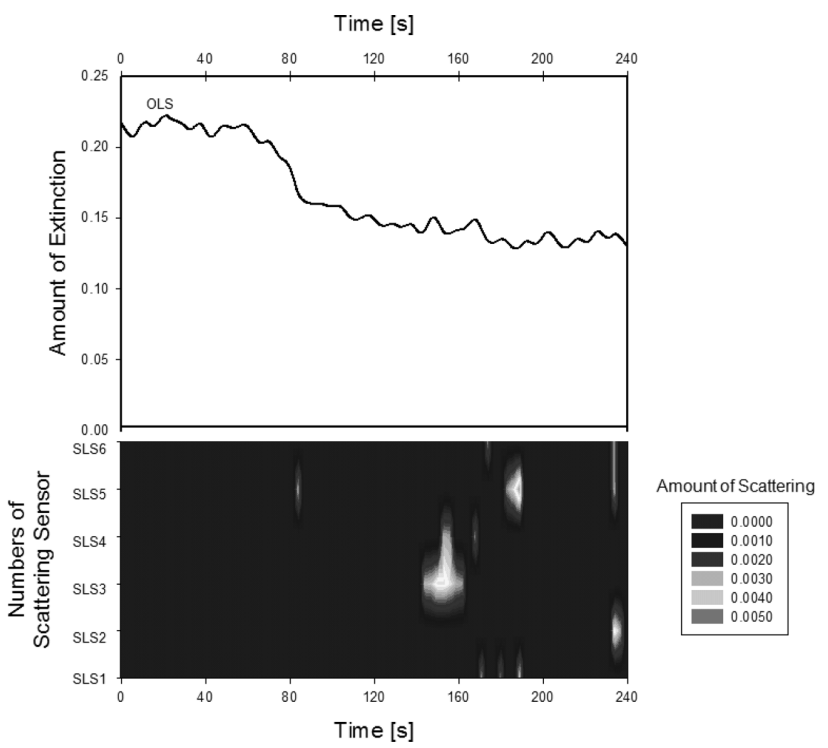

Figure 7. Amount of scattering and extinction for the wood fire.

면 목재화원에 의한 연기의 경우 모든 SLS들이 광을 감지 하였다. 이는 목재화원에 의한 연기입자들은 그 크기가 고 르지 못한 것을 의미한다. 이는 Figure 2에 있는 SEM 영 상분석결과와도 일치한다.

Figure 8은 인화성액체화원에 대한 실험결과를 보여준다. 연기감지 시작시간 $40 \mathrm{~s}$ 부터 실험이 종료될 때까지 연기는 계속해서 증가하고 있다. SLS를 보면, 산란은 연기감지를 시작한 시간 직후에 SLS6과 SLS4에서 잠깐 나타났을 뿐 그 이후 더 이상 나타나지 않았다. 측정된 산란량 또한 종 이화원이나 목재화원에 비해 매우 적었다. 인화성 액체화 원에 의한 연기는 매우 검기 때문에 산란보다 흡수가 소광 


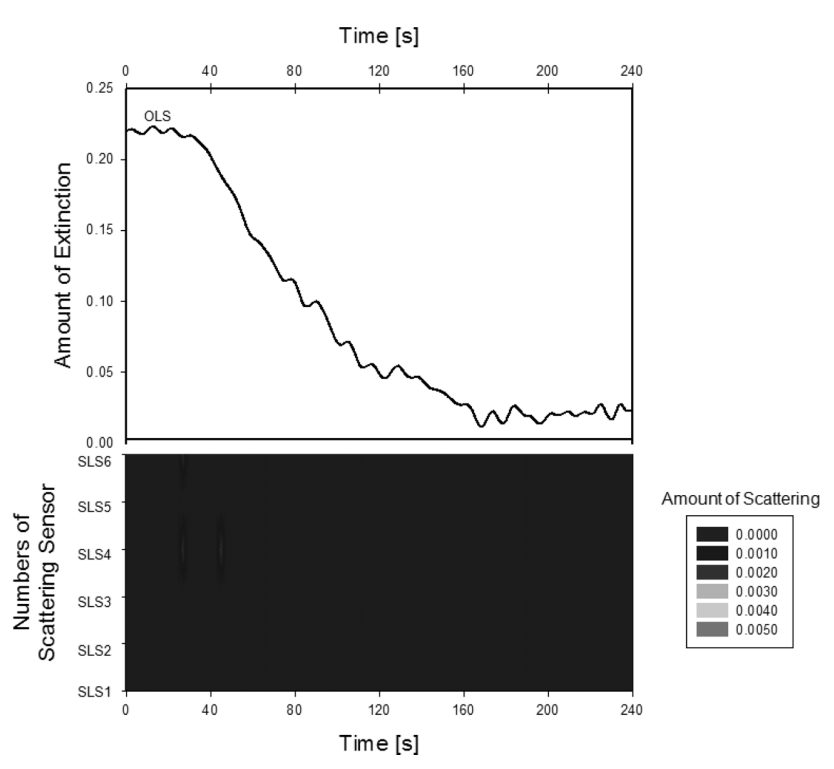

Figure 8. Amount of scattering and extinction for the flammable liquid fire.

의 주요원인으로 작용하기 때문인 것으로 생각된다. 또한 연기감지 시작시간 이후 $\mathrm{OLS}$ 는 계속 감소하지만 산란은 더 이상 감지되지 않는 영역이 존재하였다. 이러한 현상은 인화성 액체화원에 의해 발생된 연기의 가장 큰 특징이기 도 하다.

\section{5. 결 론}

본 연구는 하나의 광원에 대하여 소광을 측정하는 센서 하나와 산란을 측정하는 센서 여섯 개를 각도별로 설치하 고 광학 챔버 내로 유입된 연기를 분석하였다. 실험에 사 용된 연기는 UL 268에 따라 만들어진 종이화원, 목재화원, 인화성 액체화원이다. 소광을 기준으로 각 산란 센서가 검 출한 산란값의 분포를 분석해 각각의 연기가 가지는 광학 적 특징을 구한 결과

(1) 연기입자의 크기가 비교적 일정한 종이화원은 소광 이 시작되면서 SLS6가 가장 발달하는 경향을 보였다. 즉, 산란각의 편차가 적은 특징을 보였다.

(2) 종이 연기입자에 비해 크기와 모양이 불규칙한 목재 연기입자는 소광이 시작되면서 모든 $\mathrm{SLS}$ 들에서 산란이 검출되었다. 즉, 산란각의 편차가 큰 특징을 보였다.

(3) 연기색이 매우 검은 인화성 액체화원에 의한 연기입자 는 소광이 시작되는 초기에 잠깐 동안 산란이 있을 뿐 그 이 후부터 긴 시간동안 산란이 검출되지 않는 특징을 보였다. 즉 산란보다 흡수에 의해 빛을 소광시키는 특징을 보였다.

이상의 결과는 화재감지는 물론 화원까지 구별할 수 있는 연기감지기를 개발하는데 필요한 기초 자료가 된다. 화원을 구별 할 수 있는 감지기는 화재별 최적의 소화약재를 자동 으로 선택할 수 있는 자동화재탐지설비 개발에 필요한 기기
이다. 또한 이들 감지기 정보는 화재감식의 자료로도 활용 이 가능할 것이다. 현재는 비화재보를 비롯한 보다 다양한 화원들에 대한 특징 구별을 위한 연구가 진행되고 있다.

\section{References}

1. National Emergency Management Agency, "Safety Guides for the Automatic Fire Alarm System (NFSC 203)", Notification No. 2012-91 (2012).

2. S. W. Jee, C. H. Lee, S. K. Kim, J. J. Lee and P. Y. Kim, "Development of a Traceable Fire Alarm System Based on the Conventional Fire Alarm System", Fire Technology (DOI: 10.1007/s10694-012-0299-0 ), pp.1-18 (2012).

3. S. W. Jee, S. K. Kim, S. H. Yang, J. J. Lee, P. Y. Kim and C. H. Lee, "Detection of Fire Location and Reliability Improvement of the Conventional Fire Detector and P-type Receiver", The Korean Institute of Illuminating and Electrical Installation Engineers, Vol. 25, No. 5, pp. 39-44 (2011).

4. D. H. Baek, "Electric Installation for Fire Fighting", Dongilbook, pp. 25-191 (2007).

5. Korea Institute of Fire Industry \& Technology's Website, "http://www.kfi.or.kr/home/information/information 08.do" (2013)

6. F. Derbel, "Performance Improvement of Fire Detectors by Means of Gas Sensors and Neural Networks", Vol. 39, Issues 5, pp. 383-398 (2004).

7. R. Siebel, "Test of Fire Detection Algorithms Using Artificially Generated Events", Fire Safety Journal, Vol. 41, Issues 4, pp. 258-265 (2006).

8. S. W. Jee, S. K. Kim, J. J. Lee, P. Y. Kim and C. H. Lee, "Development of the Low Power Stand-Alone Smoke and Heat Detector for the Reliability Improvement", Journal of Korean Institute of Fire Science \& Engineering, Vol. 26, No. 1, pp. 62-68 (2011).

9. William C. Hinds, "Aerosol Technology", Translation of Korean Language, ShinKwang MunHwa Publishing Co., pp. 379-412 (1995).

10. M. Loepfe, P. Ryser, C. Tompkin and D. Wieser, "Optical Properties of Fire and Non-fire Aerosols", Fire Safety Journal, Vol. 29, Issues 2-3, pp. 185-194 (1997).

11. R. W. Bukowski, "Smoke Measurements in Large- and Small-Scale Fire Testing - Part I", Fire Technology, Vol. 15, Issue 3, pp. 173-179 (1979).

12. S. W. Jee, "Analysis of the Response Time of a Photoelectric Spot-Type Smoke Detector Depending on the Type of Fires", The Korean Institute of Illuminating and Electrical Installation Engineers, Vol. 27, No. 5, pp. 8994 (2013).

13. UL 268-2006, "Smoke Detectors for Fie Alarm Signaling Systems" (2006). 